\title{
Pengaruh Terapi Musik Klasik terhadap Respon Fisiologis pada Pasien yang Mengalami Kecemasan Praoperatif Ortopedi
}

\section{The Influence of Classical Music Therapy at Physiological Response to Patients Who Have Orthopedics Praoperatif Anxiety}

\section{Armansyah, Yecy Anggreny}

\section{Prodi Ilmu Keperawatan STIKes Hang Tuah Pekanbaru}

\begin{abstract}
ABSTRAK
Persiapan mental pasien sebelum dilakukan operasi sangat diperlukan. Apabila pasien mengalami kecemasan berat dan panik rencana operasi akan tertunda, hal tersebut memungkinkan resiko infeksi akan lebih besar. Dari berbagai penelitian menunjukan bahwa musik memiliki pengaruh yang kuat terhadap kesehatan, terutama dalam menenangkan pikiran, menurunkan ketegangan fisik dan menciptakan keadaan rileks, apabila pasien dalam keadaan rileks diharapkan dapat mempengaruhi respon fisiologis. Tujuan penelitian ini adalah untuk mengetahui pengaruh terapi musik klasik terhadap respon fisiologis pada pasien yang mengalami kecemasan praoperatif ortopedi. Desain penelitian adalah pra-eksperiment dengan jumlah sampel 30 orang menggunakan purposive sampling. Terapi musik diberikan selama \pm 30 menit. Analisis yang digunakan adalah Paired Sample T Test dan Wilcoxon. Didapatkan mean tekanan darah sistol sebelum terapi adalah 120,2 $\mathrm{mmHg}$, setelah terapi 119,6 $\mathrm{mmHg}, p$ value=0,227. Mean tekanan darah diastol sebelum terapi adalah $74,1 \mathrm{mmHg}$, setelah terapi adalah 73,2 $\mathrm{mmHg}, p$ value= 0,133. Mean frekuensi denyut jantung sebelum terapi adalah $81,8 \mathrm{x} / \mathrm{menit}$, setelah terapi adalah $79 \mathrm{x} /$ menit, $p$ value $=0,005$. Median frekuensi pernafasan sebelum terapi adalah $23 \mathrm{x} / \mathrm{menit}$, setelah dilakukan terapi adalah $21 \mathrm{x} /$ menit, nilai $p$ value $=0,001$. Hal ini menunjukkan terapi musik klasik memiliki pengaruh terhadap frekuensi denyut jantung dan frekuensi pernafasan pada pasien yang mengalami kecemasan praoperatif ortopedi. Peneliti menyarankan pemberian terapi musik klasik dengan frekuensi 2 sampai 3 kali sehari sebelum pasien menjalani operasi agar mendapatkan efek relaksasi yang optimal.
\end{abstract}

Kata Kunci : Musik Klasik, Respon Fisiologis, Kecemasan Praoperatif Ortopedi

\section{ABSTRACT}

Preparation of patients mental before to surgery is needed. If patients experience severe anxiety and panic operating plan will be delayed, it will allow a greater risk of infection. From various research show that music has a strong influence on health, especially in calming the mind, reduce physical tension and create a relaxed state, if the patient in a relaxed state is expected to affect physiological responses. The purpose of this study was to determine the effect of classical music therapy on physiological responses in patients who underwent orthopedic praoperatif anxiety. The study design is pre-experiment with a sample of 30 people using purposive sampling. Music therapy is given for \pm 30 minutes. The analysis used were Paired Sample $T$ Test and Wilcoxon. Obtained mean systolic blood pressure was $120.2 \mathrm{mmHg}$ before therapy, after therapy $119.6 \mathrm{mmHg}, p$ value $=0.227$. Mean diastolic blood pressure before treatment was $74.1 \mathrm{mmHg}, 73.2 \mathrm{mmHg}$ after therapy is, $p$ value $=0.133$. Mean heart rate before treatment was $81.8 x /$ min, after therapy was $79 x /$ minute, $p$ value $=0.005$. Median respiratory frequency before treatment was $23 x /$ minute, after the therapy is $21 x /$ minute, $p$ value $=0.001$. This shows the classical music therapy has an influence on heart rate and respiratory frequency in patients who underwent orthopedic praoperatif anxiety. Researchers recommend the use of classical music therapy with a frequency of 2 to 3 times a day before patients undergo surgery in order to obtain an optimal relaxation effects.

Keywords: Classical Music, Physiological Response, Anxiety Praoperatif Orthopedics

\section{PENDAHULUAN}

Kecemasan adalah perasaan takut yang tidak jelas dan tidak didukung oleh situasi (Videbeck, 2008). Segala bentuk prosedur pembedahan selalu didahului dengan suatu reaksi emosional tertentu oleh pasien, apakah reaksi itu jelas atau tersembunyi, normal atau abnormal. Sebagai contoh, ansietas praoperatif kemungkinan merupakan respon antisipasi terhadap semua pengalaman yang dapat dianggap pasien sebagai suatu ancaman terhadap perannya dalam hidup, integritas hidup atau bahkan kehidupannya itu sendiri, sudah diketahui bahwa pikiran yang bermasalah secara langsung mempengaruhi 
fungsi tubuh. Persiapan praoperatif penting sekali untuk mengurangi faktor resiko karena hasil suatu pembedahan sangat tergantung pada pemikiran keadaan penderita. Dalam persiapan ini ditentukan adanya kontraindikasi operasi, toleransi penderita terhadap tindakan bedah dan ditetapkannya waktu yang tepat untuk melaksanakan operasi( Sjamsuhidajat \& Jong, 2005).

Penelitian Makmuri dkk, dalam Paryanto (2009) tentang tingkat kecemasan praoperasi menunjukkan bahwa dari 40 orang responden terdapat 16 orang atau $40,0 \%$ yang memiliki tingkat kecemasan dalam kategori sedang, 15 orang atau 37,5\% dalam kategori ringan, responden dengan tingkat kecemasan berat sebanyak 7 orang atau $17,5 \%$ dan responden yang tidak merasa cemas hanya sebanyak 2 orang atau $5 \%$. Penelitian tersebut juga menunjang pendapat Smeltzer dan Bare (2002), bahwa tindakan operasi atau pembedahan merupakan pengalaman yang sulit bagi hampir semua pasien. Berbagai kemungkinan buruk bisa saja terjadi yang akan membahayakan bagi pasien. Maka tak heran jika seringkali pasien dan keluarganya menunjukkan sikap yang agak berlebihan dengan kecemasan yang mereka alami.

Musik klasik merupakan musik yang lembut, yang dapat membuat seseorang merasa rileks. Seseorang yang mendengar musik klasik akan mudah mencapai kondisi rileks dan tenang, sehingga sangat mudah menurunkan derajat kecemasan dan tingkat kekebalan tubuh (Mangoenprasodjo \& Hidayati, 2005). Efek Mozart merupakan salah satu jenis musik klasik yang manfaatnya sudah banyak diketahui. Efek Mozart muncul pada tahun 1993. Mozart merupakan jenis musik yang tidak membangkitkan gelombang untuk naik turun dan tajam. Mozart juga tidak kaku dan datar, tetapi Mozart juga tidak terlalu lembut membuai seperti pengantar tidur bayi. Kelebihankelebihan ini membuat seseorang merasa rileks ketika mendengar gubahan Mozar (Yuanitasari, 2008).

Reaksi fisiologis terhadap ansietas merupakan reaksi yang pertama timbul pada sistem saraf otonom, meliputi frekuensi nadi dan respirasi, pergeseran tekanan darah dan suhu, relaksasi otot polos pada kandung kemih dan usus, kulit dingin dan lembab, peningkatan prespirasi, dilatasi pupil dan mulut kering (Brunner \& Suddarth, 2002). Ketika mendengarkan musik, gelombang listrik yang ada diotak dapat diperlambat dan dipercepat sehingga kinerja sistem tubuh mengalami perubahan (Yuanitasari, 2008).

Musik dapat mempengaruhi denyut jantung, denyut nadi dan tekanan darah. Denyut jantung menanggapi variabel-variabel musik seperti frekuensi, tempo, dan volume dan cenderung menjadi lebih cepat atau menjadi lebih lambat bersamaan dengan ritme suatu bunyi musik.
Sebaliknya, bunyi musik yang lambat, akan membuat detak jantung semakin lambat. Detak jantung yang lebih lambat dapat menciptakan tingkat stres dan ketegangan fisik yang lebih rendah, menenangkan pikiran dan membantu tubuh untuk menyembuhkan diri sendiri (Campbell, 2001). Musik juga dapat mempengaruhi pernapasan karena pernapasan bersifat ritmis. Laju pernapasan yang lebih dalam dan lebih lambat sangat baik dalam menimbulkan ketenangan, kendali emosi, pemikiran yang lebih dalam, dan metabolisme yang lebih baik. Pernapasan yang dangkal dan cepat dapat membawa pada cara berpikir yang superfisial, dan terpecah-pecah, perilaku impulsif, dan kecenderungan untuk membuat kesalahan. Pemberian musik dengan memperlambat tempo musik atau dengan mendengarkan musik yang bunyinya lebih panjang dan lebih lambat, orang lazimnya mampu memperdalam dan memperlambat pernapasan, sehingga memungkinkan pikiran menjadi tenang (Campbell, 2001).

Penelitian ini bertujuan untuk mengetahui pengaruh terapi musik klasik terhadap respon fisiologis (tekanan darah, frekuensi denyut jantung dan frekuensi pernafasan) pada pasien yang mengalami kecemasan praoperatif ortopedi.

\section{METODE}

Jenis penelitian ini adalah kuantitatif, menggunakan pendekatan Pra-post test dalam satu kelompok (One-Group Pra-test-Posttest design) untuk mengungkap hubungan sebab akibat dengan cara melibatkan satu kelompok subjek dengan desain praeksperiment. Penelitian ini dilakukan di Rumah Sakit Arifin Achmad Provinsi Pekanbaru mulai tanggal 28 mei sampai dengan 25 juni 2011. Populasi dalam penelitian ini adalah pasien praoperasi ortopedi dengan jumlah sampel 30 orang. Sampel diambil dengan cara purposive sampling.

Pada penelitian ini, pengumpulan data menggunakan lembar observasi kecemasan dan lembar observasi respon fisiologis secara langsung kepada responden penelitian untuk mencari perubahan atau hal-hal yang akan diteliti. Alat ukur yang digunakan pada penelitian ini berupa alat mekanik yaitu earphonel headset dan sphygmomanometer digital yang sudah melalui uji kalibrasi alat. Terapi musik dilakukan sebelum responden operasi dengan durasi \pm 30 menit. Analisis data dilakukan secara univariat dan bivariat dengan uji Paired Sample T Test untuk membandingkan dua mean sebelum dan setelah dilakukan terapi musik klasik dan uji wilcoxon untuk membandingkan perbedaan dua median sebelum dan setelah diberikan terapi musik klasik. 


\section{HASIL}

\section{Respon Fisiologis Pasien Praoperatif Sebelum Mendengarkan Musik Klasik}

Mean tekanan darah sistolik sebelum terapi adalah 120,2 $\mathrm{mmHg}$, mean tekanan darah diastolik sebelum terapi adalah $74,1 \mathrm{mmHg}$ dan mean frekuensi denyut jantung sebelum terapi adalah $81,8 \mathrm{x} /$ menit, sedangkan median frekuensi pernafasan sebelum terapi adalah $23 \mathrm{x} /$ menit (lihat tabel 1).

\section{Respon Fisiologis Pasien Praoperatif Setelah Mendengarkan Musik Klasik}

Mean tekanan darah sistolik setelah terapi adalah 119,9 $\mathrm{mmHg}$, mean tekanan darah diastolik setelah terapi musik klasik adalah $73,2 \mathrm{mmHg}$ dan mean frekuensi denyut jantung setelah terapi musi klasik adalah $79 \mathrm{x} /$ menit, sedangkan median frekuensi pernafasan setelah terapi musik klasik adalah 21 $\mathrm{x} /$ menit (lihat tabel 2).

\section{Pengaruh Terapi Musik Klasik terhadap Respon Fisiologis}

Dari hasil uji statistik didapat standar deviasi tekanan darah sistolik pra-test terapi adalah 10,950. Standar deviasi Tekanan darah sistolik post-test terapi musik klasik 10,949 dengan nilai $p$ value $=0,227$ sedangkan standar deviasi tekanan darah diastolik pratest terapi musik klasik adalah 8,953 . Standar deviasi tekanan darah diastolik post-test terapi musik klasik adalah 3,070 dengan nilai $p$ value $=0,133$. Standar deviasi frekuensi denyut jantung pra-test terapi musik klasik adalah 9,338. Standar deviasi denyut jantung post-test terapi musik klasik adalah 8,102 , dengan nilai $p$ value $=0,005$ (lihat tabel 3 ).

\section{Pengaruh Terapi Musik Klasik terhadap Perubahan Frekuensi Pernafasan}

Uji statistik menunjukkan bahwa perbedaan frekuensi pernafasan didapat median pra-test terapi adalah $23 \mathrm{x} /$ menit dan median post-test terapi adalah $21 \mathrm{x} /$ menit, nilai $p$ value $=0,001$ (lihat tabel 4).

Tabel 1

Distribusi Frekuensi Respon Fisiologis Pasien Praoperatif Sebelum Mendengarkan Musik Klasik

\begin{tabular}{|c|c|c|c|c|c|}
\hline \multirow[b]{2}{*}{ Respon fisiologis } & \multicolumn{5}{|c|}{ Pasien praoperatif sebelum mendengarkan musik klasik } \\
\hline & $\mathbf{N}$ & Nilai minimum & Nilai maksimum & Mean & Median \\
\hline Tekanan darah sistolik & & 96 & 124 & 120,2 & \\
\hline Tekanan darah diastolik & 30 & 60 & 90 & 74,1 & \\
\hline Frekuensi denyut jantung & & 67 & 100 & 81,8 & \\
\hline Frekuensi pernafasan & & 18 & 26 & & 23 \\
\hline
\end{tabular}

Tabel 2

Distribusi Frekuensi Respon Fisiologis Pasien Praoperatif Sebelum Mendengarkan Musik Klasik

\begin{tabular}{|c|c|c|c|c|c|}
\hline \multirow[b]{2}{*}{ Respon fisiologis } & \multicolumn{5}{|c|}{ Pasien praoperatif setelah mendengarkan musik klasik } \\
\hline & $\mathbf{N}$ & Nilai minimum & Nilai maksimum & Mean & Median \\
\hline Tekanan darah sistolik & & 60 & 90 & 119,6 & \\
\hline Tekanan darah diastolik & 30 & 60 & 91 & 73,2 & \\
\hline Frekuensi denyut jantung & & 66 & 100 & 79 & \\
\hline Frekuensi pernafasan & & 16 & 24 & & 21 \\
\hline
\end{tabular}

Tabel 3.

Pengaruh Terapi Musik Klasik terhadap Perubahan Respon Fisiologis

\begin{tabular}{lccccc}
\hline \multirow{2}{*}{ Respon fisiologis } & \multicolumn{2}{c}{ Pra-test } & \multicolumn{2}{c}{ Post-test } & \multirow{2}{*}{$\boldsymbol{p}$ value } \\
\cline { 2 - 5 } & Mean & SD & Mean & SD & \multirow{2}{*}{0,227} \\
Tekanan darah sistolik & 120,2 & 10,950 & 119,6 & 10,949 & 0,133 \\
Tekanan darah diastolik & 74,1 & 8,953 & 73,2 & 8,803 & 0,005 \\
Frekuensi denyut jantung & 81,8 & 9,338 & 79 & 8,102 & 0,005 \\
\hline
\end{tabular}

Tabel 4.

Pengaruh Terapi Musik Klasik terhadap Perubahan Frekuensi Pernafasan

\begin{tabular}{cccc}
\hline \multirow{2}{*}{ Respon fisiologis } & Pra-test & Post-test & \multirow{2}{*}{$\boldsymbol{p}$ value } \\
\cline { 2 - 3 } Rata-rata frekuensi pernafasan & Median & Median & \\
\hline
\end{tabular}




\section{PEMBAHASAN}

\section{Tekanan Darah Sistolik dan Diastolik}

Berdasarkan uji statistik pengaruh mendengarkan musik klasik terhadap perubahan respon fisiologis didapatkan mean tekanan darah sistolik pra-test adalah $120,2 \mathrm{mmHg}$, sedangkan mean tekanan darah sistolik post-test adalah $119,6 \mathrm{mmHg}$ dengan nilai $p$ value $=0,227$ dan untuk mean tekanan darah diastolik pra-test adalah $74,1 \mathrm{mmHg}$, sedangkan mean tekanan darah diastolik post-test adalah 73,2 mmHg dengan hasil ukur menunjukkan nilai $p$ value $=$ 0,133 . Hal ini menunjukkan bahwa musik klasik tidak berpengaruh terhadap tekanan darah sistolik dan diastolik pada pasien praoperasi ortopedi.

Dari uji statistik yang menunjukkan tidak ada pengaruh signifikan antara tekanan darah (sistolik dan diastolik) baik sebelum maupun setelah diberikan terapi musik klasik karena beberapa responden tidak begitu menyukai jenis musik klasik, selain itu terapi musik yang diberikan hanya satu kali. Diagnosa klien tidak sama, sehingga pasien praoperasi memiliki karakteristik dan tingkat kecemasan yang berbeda. Untuk mendapatkan hasil yang signifikan peneliti menganjurkan agar musik klasik dapat diputar lebih dari sekali atau waktu terapi dapat dilakukan 2 sampai 3 kali sehari sebelum pasien menjalankan operasi agar mendapatkan hasil yang optimal.

Dari hasil penelitian diatas sesuai dengan penelitian yang dilakukan oleh Murni (2010) tentang efektifitas terapi musik klasik dalam menurunkan tekanan darah, dalam waktu yang sama dengan peneliti lakukan yaitu selama \pm 30 menit tetapi selama 7 kali pertemuan secara berkesinambungan. Hasil penelitian didapatkan mean tekanan darah sebelum terapi pada kelompok eksperimen dan kontrol adalah 118,6 mmHg dan $115,2 \mathrm{mmHg}$ setelah diberikan terapi mean menjadi $112,3 \mathrm{mmHg}$ dan $117,8 \mathrm{mmHg}$. Hal tersebut menunjukkan bahwa mean tekanan darah pada kelompok eksperimen lebih kecil dari pada kelompok kontrol sehingga dapat disimpulkan bahwa musik klasik memiliki pengaruh yang signifikan dalam menurunkan tekanan darah.

\section{Frekuensi Denyut Jantung.}

Uji statistik perubahan respon fisiologis didapatkan mean frekuensi denyut jantung pra-test adalah $81,8 \mathrm{x} /$ menit, sedangkan mean frekuensi denyut jantung post-test adalah $79 \mathrm{x} /$ menit dengan hasil ukur menunjukkan nilai $p$ value $=0,005$. Hal ini menunjukkan musik klasik memiliki pengaruh signifikan terhadap frekuensi denyut jantung pada pasien praoperasi ortopedi.

Perubahan gelombang otak dengan sendirinya juga akan mengubah fungsi tubuh lainnya yang diatur oleh sistem saraf otonom misalnya, detak jantung dapat berubah akibat jenis musik yang berbeda. Hal ini bisa berdampak pada proses bernapas yang semakin lambat, detak jantung juga semakin lambat, serta adanya respon relaksasi (Rusdi \& Isnawati, 2009).

\section{Frekuensi Pernafasan}

Uji statistik perubahan respon fisiologis didapatkan median frekuensi pernafasan pra-test adalah $23 \mathrm{x} /$ menit, sedangkan median frekuensi pernafasan post-test adalah $21 \mathrm{x} /$ menit dengan hasil ukur menunjukkan nilai $p$ value $=0,001$. Hal ini menunjukkan musik klasik memiliki pengaruh signifikan terhadap frekuensi pernafasan pada pasien praoperasi ortopedi.

Penelitian lain menunjukan bahwa pernapasan juga dapat dipengaruhi musik karena pernapasan bersifat ritmis. Laju pernapasan yang lebih dalam dan lebih lambat sangat baik dalam menimbulkan ketenangan, kendali emosi, pemikiran yang lebih dalam, dan metabolisme yang lebih baik. Pernapasan yang dangkal dan cepat dapat membawa pada cara berpikir yang superfisial, dan terpecah-pecah, perilaku impulsif, dan kecenderungan untuk membuat kesalahan. Tempo musik yang lebih lambat atau dengan mendengarkan musik yang bunyinya lebih panjang, orang lazimnya mampu memperdalam dan memperlambat pernapasan, sehingga memungkinkan pikiran menjadi tenang (Campbell, 2001).

\section{KESIMPULAN}

Tidak ada pengaruh yang bermakna antara terapi musik klasik dengan tekanan darah sistolik dan diastolik pada pasien yang mengalami kecemasan praoperatif ortopedi tetapi ada pengaruh yang bermakna antara terapi musik klasik dengan frekuensi denyut jantung dan frekuensi pernapasan pada pasien yang mengalami kecemasan praoperatif ortopedi.

\section{SARAN}

\section{Bagi Rumah Sakit}

Bagi institusi kesehatan terutama rumah sakit, hasil penelitian ini dapat disosialisasikan dalam penanganan pasien yang mengalami kecemasan dimana mendengarkan musik klasik sebagai salah satu bentuk terapi relaksasi bagi pasien praoperatif ortopedi.

\section{Bagi Pasien Praoperatif Ortopedi}

Bagi pasien praoperatif, hasil penelitian ini dapat digunakan sebagai salah satu bentuk terapi relaksasi yang dapat digunakan untuk membuat pasien praoperatif ortopedi lebih rileks dalam menghadapi operasi. Peneliti menganjurkan untuk memberikan terapi musik lebih baik disesuaikan dengan jenis musik yang disukai pasien dan waktu terapi dapat ditambah baik dalam sehari maupun porsi dalam sekali terapi, sehingga memiliki efek relaksasi yang lebih lama. 


\section{Bagi Peneliti Selanjutnya}

Bagi peneliti selanjutnya, hasil penelitian ini dapat dijadikan sebagai data, informasi dasar dan evidence based untuk melaksanakan penelitian lebih lanjut. Peneliti menganjurkan agar dapat membandingkan dengan jenis musik lainnya dan tata cara terapi maupun waktu pemberian terapi yang lebih baik.

\section{DAFTAR PUSTAKA}

Campbell, D. (2001). Efek mozart: Memanfaatkan Kekuatan Musik Untuk Mempertajam Pikiran, Meningkatkan Kreativitas, dan Menyehatkan Tubuh. Jakarta: Gramedia Pustaka Utama.

Hidayat, A. A. (2006). Pengantar Kebutuhan Dasar Manusia: Aplikasi Konsep dan Proses Keperawatan. Jakarta: salemba medika.

Hidayat, A. A. (2007). Metode Penelitian Keperawatan dan Teknik Analisis Data. Jakarta: Salemba Medika.

Mangoenprasodjo, A. S., \& Hidayati, N. S. (2005). Terapi Alternatif dan Gaya Hidup Sehat. Jogjakarta: Pradipta.

Murni. (2010). Efektifitas Terapi Musik Klasik Dalam Menurunkan Tekanan Darah Pada Penderita Hipertensi. Skripsi, UR.
Paryanto. (2009). Perbedaan Tingkat Kecemasan Pasien Pre operatif Selama Menunggu Jam Operasi Antara Ruang Rawat Inap Dengan Ruang Persiapan Operasi Rumah Sakit di Surakarta. Surakarta : Fakultas Ilmu Kesehatan Universitas Muhammadiyah Surakarta. Dari http://etd.eprints.ums.ac.id/4496/. Diperoleh tanggal 20 Oktober 2010.

Rusdi, \& Isnawati, N. (2009). Awas! Anda Bisa Mati Cepat Akibat Hipertensi dan Diabetes. Jogjakarta : Power Books.

Setiawati, S., \& Dermawan, A., C. (2009). Keterampilan Khusus Praktik keperawatan Anak. Jakarta: TIM.

Sjamsuhidajat, R. \& jong, W.D. (2005). Buku Ajar Ilmu Bedah. Ed. 2. Jakarta: EGC.

Smeltzer, Suzanne C. \& Brenda G. Bare (2002). Buku Ajar Keperawatan Medikal Bedah: Brunner Suddarth, Vol. 1. Jakarta: EGC.

Smeltzer, Suzanne C. \& Brenda G. Bare (2002). Buku Ajar Keperawatan Medikal Bedah: Brunner Suddarth, Vol. 3. Jakarta: EGC.

Videbeck, S.J. (2008). Buku Ajar Keperawatan Jiwa. Jakarta : EGC.

Yuanitasari, L. (2008). Terapi Musik Untuk Anak Balita. Jogjakarta: Cemerlang. 